\title{
Macrophage Activation Syndrome in Two Infants with Multisystem Inflammatory Syndrome in Children
}

\author{
MIGUEL GARCIA DOMINGUEZ ${ }^{1}$, Cynthia Torres ${ }^{1}$, Juan Carreón-Guerrero ${ }^{1}$, Jose \\ Quibrera $^{1}$, Daniela Arce-Cabrera ${ }^{1}$, and Marco Yamazaki-Nakashimada ${ }^{2}$ \\ ${ }^{1}$ Hospital Pediatrico de Sinaloa \\ ${ }^{2}$ National Institute of Pediatrics
}

May 5, 2021

\begin{abstract}
Multisystem inflammatory syndrome in children (MIS-C) associated with SARS-CoV-2 infection with clinical features of Kawasaki-like disease was reported in various pediatric centers in late April 2020. Currently, cases have increased throughout the world with a range of manifestations from less to greater severity. However, hemophagocytosis has not been described in patients with MIS-C. We describe two infants diagnosed with MIS-C who presented Macrophage Activation Syndrome (MAS) with hemophagocytosis documented in the bone marrow. MIS-C can be complicated with MAS, the key features for diagnosis are splenomegaly, hypofibrinogenemia, hypertriglyceridemia and bone marrow hemophagocytosis. Cytokine storm and MAS in MIS-C may represent part of the spectrum of the disease and HScore could be of value in order to give timely and aggressive treatment.
\end{abstract}

\section{Introduction}

COVID-19 infection emerged in Wuhan, China in December 2019 (1) and rapidly expanded worldwide as a cause of severe acute respiratory syndrome (SARS-CoV-2), affecting more severely older adults with comorbidities. In late April 2020 severe forms of SARS-CoV-2 infection in children with shock and Kawasaki disease-like features $(2,3)$ were reported in the UK and Italy. In the initial report, macrophage activation syndrome (MAS) features were described in 5 of 10 patients diagnosed with this complication (3). However, hemophagocitosis has not been described in patients with MIS-C. We report two infants diagnosed with MIS-C who presented MAS who responded to biological and immunosuppressants therapies.

\section{Case 1}

A previously healthy 6-month-old girl presented a three-day history of high-grade fever, irritability and vomiting. Upon admission, myoclonic movements of both hands, oral aphthae, and conjunctival erythema in the right eye were noticed. Due to clinical suspicion of encephalitis, a lumbar puncture was performed which showed pleocytosis with WBC count $141 \mathrm{~mm}^{3}, 75 \%$ monocytes, $15 \% \mathrm{PMN}$, glucose $73 \mathrm{mg} / \mathrm{dL}$, protein $181 \mathrm{mg} / \mathrm{dL}$ and LDH $50 \mathrm{U} / \mathrm{L}$. Complete blood count revealed WBC 14,350/ $\mathrm{mm}^{3}$ (75\% PMN, $20.6 \%$ lymphocytes), $\mathrm{Hb} 9.7 \mathrm{~g} / \mathrm{dL}$, platelets $110,000 / \mathrm{mm}^{3}$, CRP $10 \mathrm{mg} / \mathrm{dL}$, procalcitonin $7.5 \mathrm{ng} / \mathrm{mL}$, UA showed leukocyturia. The patient received treatment with cefotaxime and vancomycin. High fever persisted with vomiting and generalized erythematous rash. COVID-19 was suspected, a CT of the chest showed right lung apical consolidation and subsegmental atelectasis with subsegmental pneumonic foci in the left lung (Figure 1A). Subsequent laboratory tests showed WBC $29,900 / \mathrm{mm}^{3}$, PMN 23,390/ $\mathrm{mm}^{3}(78 \%)$, lymphocytes $6,010 / \mathrm{mm}^{3}$, $\mathrm{Hb} 10.2 \mathrm{~g} / \mathrm{dL}$, platelets $107,000 / \mathrm{mm}^{3}$, CRP $16.7 \mathrm{mg} / \mathrm{dL}$, ESR $37 \mathrm{~mm} / \mathrm{hr}$, procalcitonin $46.3 \mathrm{ng} / \mathrm{mL}$, albumin $1.9 \mathrm{~g} / \mathrm{dL}$, D-dimer $3.49 \mathrm{mg} / \mathrm{mL}$, NT-proBNP $2.916 \mathrm{pg}$, Troponin I $<10 \mathrm{pg} / \mathrm{mL}$, fibrinogen $125 \mathrm{mg} / \mathrm{dL}$, with positive IgG and negative nasopharyngeal RT-PCR for SARS-CoV-2. The diagnosis of MIS-C was made 
and treatment with IVIG $(2 \mathrm{~g} / \mathrm{kg})$, three boluses of methylprednisolone (30 mg $/ \mathrm{kg} / \mathrm{dose})$ and enoxaparin (1 $\mathrm{mg} / \mathrm{kg} /$ dose) was started. The echocardiogram reported LVEF 59\%, mild mitral and tricuspid regurgitation, with mild pericardial effusion, with normal coronary arteries.

On day 9 he presented increased respiratory effort, continuous fever, hypotension and lactic acidosis. The CT scan showed an increase in bilateral pulmonary infiltrate (Fig. 2), hepatomegaly and splenomegaly of $4 \mathrm{~cm}$ below the costal border. Laboratory test showed WBC $47,720 / \mathrm{mm}^{3}$, PMN $41,800 / \mathrm{mm}^{3}(87.5 \%)$,

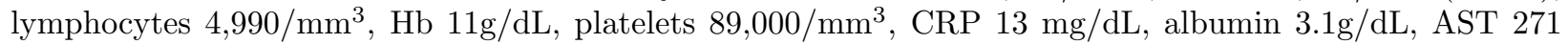
$\mathrm{U} / \mathrm{L}$, ALT $351 \mathrm{U} / \mathrm{L}$, total bilirubin $0.61 \mathrm{mg} / \mathrm{dL}$, indirect bilirubin $0.15 \mathrm{mg} / \mathrm{dL}$, D-dimer $6.36 \mathrm{mcg} / \mathrm{mL}$, NTproBNP $12.347 \mathrm{pg}$, ferritin $2.204 \mathrm{ng} / \mathrm{mL}$, fibrinogen $105 \mathrm{mg} / \mathrm{dL}$, negative blood cultures. A second dose of IVIG $(2 \mathrm{~g} / \mathrm{kg})$ and three consecutive methylprednisolone pulses were administered.

Due to the presence of persistent fever, hyperferritinemia, anemia and thrombocytopenia, hypofibrinogenemia, elevated transaminases, a bone marrow aspiration was performed with evidence of four hemophagocytic cells (figure 2), HScore was 243. The patient received dexamethasone $10 \mathrm{mg} / \mathrm{m}^{2} /$ day and cyclosporine-A (3 $\mathrm{mg} / \mathrm{kg} /$ day). After 72 hours the IL-6 level was $63.1 \mathrm{pg} / \mathrm{mL}$ and the patient received tocilizumab $12 \mathrm{mg} / \mathrm{kg} /$ day and a second dose after $12 \mathrm{hrs}$. Clinical improvement was observed within 24 to 36 hours with normalization of fever, respiratory failure, and inflammatory biomarkers. On follow-up, all medications were suspended and a new bone marrow aspiration was performed at day 28 of presentation, with no evidence of hemophagocytosis (Figure 2C).

\section{Case 2}

A 5-month-old girl developed five days before admission high fever, pallor, irritability, nausea, vomiting, diarrhea and a perianal dermatosis. Clinically she was lethargic, dehydrated, with generalized pallor, tachypnea and bilateral rales, cervical, axillar and inguinal lymphadenopathies, hepatosplenomegaly and week periph-

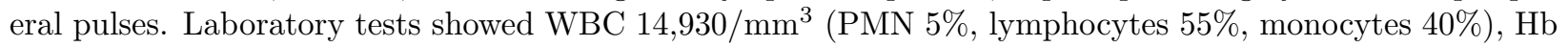
$3.7 \mathrm{~g} / \mathrm{dL}$, platelet count $8,000 / \mathrm{mm}^{3}$, albumin $2.3 \mathrm{~g} / \mathrm{dL}$, total bilirubin $1.1 \mathrm{mg} / \mathrm{dL}$, CRP $37.1 \mathrm{mg} / \mathrm{dL}$, procalcitonin $11 \mathrm{ng} / \mathrm{mL}$, ferritin 2,290 ng/mL and fibrinogen $398 \mathrm{mg} / \mathrm{dL}$. Treatment was initiated with cefotaxime and vancomycin, a chest CT was performed with findings suggestive of COVID-19 infection, with interstitial infiltrates, ground-glass opacities bronchoalveolar thickening and left subsegmental atelectasis (Fig 1B). Laboratory tests showed a D-dimer $6.52 \mu \mathrm{g} / \mathrm{mL}$, NT-proBNP $207 \mathrm{pg} / \mathrm{mL}$, Troponin I $<10 \mathrm{pg} /$ with positive immunoglobulin IgG serology and negative RT-PCR for SARS-CoV-2; the echocardiogram reported LVEF $48 \%$. The diagnosis of MIS-C was made and received treatment with IVIG $(2 \mathrm{~g} / \mathrm{kg})$, three boluses of methylprednisolone $(30 \mathrm{mg} / \mathrm{kg} /$ dose $)$ and enoxaparin $(1 \mathrm{mg} / \mathrm{kg} /$ dose $)$.

She had persistent fever, bicytopenia with anemia and thrombocytopenia, albumin $2.9 \mathrm{~g} / \mathrm{dL}$, total bilirubin $0.67 \mathrm{mg} / \mathrm{dL}$, CRP $1.6 \mathrm{mg} / \mathrm{dL}$, procalcitonin $0.53 \mathrm{ng} / \mathrm{mL}$, D-dimer $6.14 \mathrm{mcg} / \mathrm{mL}$, ferritin $1000 \mathrm{ng} / \mathrm{mL}$, NTproBNP $428 \mathrm{pg} / \mathrm{mL}$ triglycerides $531 \mathrm{mg} / \mathrm{dL}$, fibrinogen $159 \mathrm{mg} / \mathrm{dL}$, IL-6 levels in $4.52 \mathrm{pg} / \mathrm{mL}(<9.7)$; she developed multi-organ failure despite treatment and had significant hepatosplenomegaly. A bone marrow aspiration was performed with hemophagocytosis (Figure 3); HScore was 224. A second dose of IVIG was administrated and had induction treatment according to HLH 2004 Protocol with low dose etoposide and dexamethasone. Blood cultures grew Serratia marcescens was treated with meropenem. Clinical improvement was seen after 72 hours and the patient had a favorable response after six weeks of chemotherapy with normalization of CBC; follow-up, all medications were stopped and a new bone marrow biopsy showed normal findings (Figure 3C). Primary Hemophagocytic lymphohistiocytosis (HLH) was ruled out with nextgeneration sequencing.

\section{Discussion}

MIS-C was described at the end of April 2020 as a hyperinflammatory syndrome like-KD, since then thousands of cases have been described in various centers around the world $(2,3)$.

In adults, COVID-19 acute infection can present as a severe form known as cytokine storm syndrome (CS), with alveolar macrophage activation with release of TNF- $\alpha$, IL-1 $\beta$, IL-6, with systemic inflammatory 
response and multiorgan dysfunction (4). ). In a postmortem study of severe COVID-19 in adults, three of the four cases had histologic evidence of hemophagocytosis in pulmonary lymph nodes, one case had hemophagocytosis in the spleen, but none had hemophagocytosis in the liver or bone marrow (5).

In an autopsy retrospective single-center study, patients who tested positive for COVID-19; hemophagocytosis, ranging from rare to many scattered cells, was identified histologically on H\&E and/or CD68 immunohistochemical stains in all of 19 study patients (6). In contrast, Wood et al. and Lorenz et al. reported that secondary HLH is rare in severe adult COVID-19 patients $(7,8)$. Splenomegaly, a frequent feature of HLH, is rare in CS COVID-19 patients; in fact, autopsies show a reduction of spleen volume and white pulp, lymphocyte apoptosis and splenic thrombosis without evidence of hemophagocytosis (4).

MAS, a term used interchangeably with sHLH, is a potentially fatal complication of infectious and rheumatological diseases including Kawasaki disease (KD). MAS occurs in 1.9-4.7\% of KD patients (10).

A validated risk calculator known as the HScore is used to identify those patients with a high probability of a diagnosis of MAS and guide immunosuppressive therapy (11). The HScore carries a diagnostic sensitivity of $90 \%$, and specificity of $79 \%$ for HLH. This score have proved to be valuable for the diagnosis of MAS in systemic juvenile idiopathic arthritis patients (12). Mirroring KD, we believe that our two patients with high HScore and the transient nature of the disease presented MAS as a complication of MIS-C. HScore has been explored in severe COVID-19 in adults and has been limited value in guiding immunomodulatory therapy (13).

Our two patients presented a HScore compatible with MAS, with eatures not usually described in MIS-C including hypofibrinogenemia, splenomegaly and bone marrow hemophagocytosis .

Lee et al. performed a retrospective study of patients with MIS-C and compared them with historic cohorts of MAS associated with systemic juvenile idiopathic arthritis or infection and found that soluble IL-12, ferritin, IL-18 and CXCL9 elevations were higher in MAS compared to MIS-C, concluding that MIS-C immunological features do not appear to resemble MAS (14).

The optimal treatment for MAS has not been defined. In our first case, a combined treatment with IVIG, cyclosporin-A, corticosteroids and tocilizumab led to resolution of the disease. Cyclosporin-A has been used in refractory KD and is an integral part of $\operatorname{HLH}$ treatment $(9,10,15)$. The second case proved to be more aggressive and the decision to give etoposide was made. Interestingly, etoposide was recently used successfully in a 66-year-old patient with CS in COVID-19 resistant to multiple anti-cytokine therapy (16).

MIS-C has been considered part of the KD spectrum, paralleling features of KD such as the presence of coronary aneurysms, the development of shock, and as in our cases the development of MAS as a lifethreatening complication (17). MIS-C can be complicated with MAS, disease awareness is essential; with splenomegaly, hypofibrinogenemia, hypertriglyceridemia and bone marrow hemophagocytosis as key features to suspect this complication. CSS and MAS in MIS-C may represent a spectrum of the disease. HScore could be of value in order to provide timely and aggressive treatment.

Acknowledgments

The authors thank Dr. Alberto Unzueta for editing and helpful discussions regarding this manuscript.

\section{REFERENCES}

1. Zhu N, Zhang D, Wang W, Li X, Yang B, Song J, Zhao X, et al. A novel coronavirus from patients with pneumonia in China, 2019. N Engl J Med. 2020;382(8):727-733.

2. Riphagen S, Gomez X, Gonzalez-Martinez C, Wilkinson N, Theocharis P. Hyperinflammatory shock in children during COVID-19 pandemic. Lancet. 2020;395(10237):1607-1608.

3. Verdoni L, Mazza A, Gervasoni A, Martelli L, Ruggeri M, Ciuffreda M, Bonanomi E, et al. An outbreak of severe Kawasaki-like disease at the Italian epicentre of the SARS-CoV-2 epidemic: an observational cohort study. Lancet. 2020;395(10239):1771-1778. 
4. Satturwar S, Fowkes M, Farver C, Wilson AM, Eccher A, Girolami I et al. Postmortem Findings Associated With SARS-CoV-2: Systematic Review and Meta-analysis. Am J Surg Pathol 2021 Jan 20. doi:10.1097/PAS.0000000000001650. Online ahead of print.

5. Harris CK, Hung YP, Nielsen GP, Stone JR, Ferry JA. Bone Marrow and Peripheral Blood Findings in Patients Infected by SARS-CoV-2. Am J Clin Pathol. 2021 Jan 27:aqaa274. doi: 10.1093/ajcp/aqaa274. Online ahead of print.

6. Prilutskiy A, Kritselis M, Shevtsov A, Yambayev I, Vadlamudi C, Zhao Q, Kataria Y, Sarosiek SR, Lerner A, Sloan JM, Quillen K, Burks EJ. SARS-CoV-2 Infection-Associated Hemophagocytic Lymphohistiocytosis.Am J Clin Pathol. 2020 Sep 8;154(4):466-474. doi: 10.1093/ajcp/aqaa124.

7. Lorenz G, Moog P, Bachmann Q, La Rosee P, Schneider H, Schlegl M, Spinner C, Heemann U, SchmidRM, Algül H, Lahmer T , W , SchmadererC. Cytokine release syndrome is not usually caused by secondary hemophagocytic lymphohistiocytosis in a cohort of 19 critically ill COVID-19 patients. Sci Rep2020 Oct 26;10(1):18277. doi: 10.1038/s41598-020-75260-w.

8. Wood H, Jones JR, Hui K, Mare T, Pirani T, Galloway J, Metaxa V, Benjamin R, Rutherford A, Cain S, Kulasekararaj AG. Secondary HLH is uncommon in severe COVID-19. Br J Haematol. 2020 Sep;190(5):e283-e285. doi: 10.1111/bjh.16934. Epub 2020 Aug 10.

9. Garcia-Pavon S, Yamazaki-Nakashimada MA, Baez M, Borjas-Aguilar KL, Murata C: Kawasaki disease complicated with macrophage activation syndrome: a systematic review. J Pediatr Hematol Oncol. 2017, 39:445-451.

10. Ulloa-Gutierrez R, Alphanse MP, Dharanja A, Yeung RS, Kawasaki disease associated cytokine storm syndrome. Cytokine Storm Syndrome, Springer 2019, 393.

11. Fardet L, Galicier L, Lambotte O, Marzac C, Aumont C, Chahwan D, Coppo P, Hejblum G. Development and validation of the HScore, a score for the diagnosis of reactive hemophagocytic syndrome. Arthritis Rheumatol 2014 Sep;66(9):2613-20. doi: 10.1002/art.38690.

12. Sag, E., Keskin, A., Atalay, E., Demir, S., Cuceoglu, M. K., Akca, U. K., .. Ozen, S. (2020). Performances of the "MS-score" And "HScore" in the diagnosis of macrophage activation syndrome in systemic juvenile idiopathic arthritis patients. Rheumatology International. doi:10.1007/s00296-02004750-x

13. Clark, K. E. N., Nevin, W. D., Mahungu, T., Lachmann, H., \& Singh, A. (2020). Assessment of the Haemophagocytic lymphohistiocytosis HScore in patients with COVID-19. Clinical Infectious Diseases. doi:10.1093/cid/ciaa1463

14. Lee PY, Day-Lewis M, Henderson LA, Friedman KG, Lo J, Roberts JE, Lo MS, Platt CD, Chou J, Hoyt KJ, Baker AL, Banzon TM, Chang MH, Cohen E, de Ferranti SD, Dionne A, Habiballah S, Halyabar O, Hausmann JS, Hazen MM, Janssen E, Meidan E, Nelson RW, Nguyen AA, Sundel RP, Dedeoglu F, Nigrovic PA, Newburger JW, Son MBF. Distinct clinical and immunological features of SARS-CoV-2induced multisystem inflammatory syndrome in children. J Clin Invest. 2020 Nov 2;130(11):5942-5950. doi: 10.1172/JCI141113.

15. Hamada H, Suzuki H, Onuichi Y, Ebata R, Terai M, Fuse S et al. Efficacy of primary treatment with immunoglobulin plus ciclosporin for prevention of coronary artery abnormalities in patients with Kawasaki disease predicted to be at increased risk of non-response to intravenous immunoglobulin (KAICA): a randomised controlled, open-label, blinded-endpoints, phase 3 trial. Lancet 2019 Mar 16;393(10176):1128-1137. doi: 10.1016/S0140-6736(18)32003-8.

16. Patel M, Dominguez E, Sacher D, Desai P, Chandar A, Bromberg M et al. Etoposide as Salvage Therapy for Cytokine Storm Due to Coronavirus Disease 2019. Chest 2021 Jan;159(1):e7-e11. doi: 10.1016/j.chest.2020.09.077.

17. Yeung RS, Ferguson PJ. Is myltisystem inflammatory syndrome in children on the Kawasaki syndrome spectrum?. The Journal of Clinical Investigation. 2020;130(11):5681-5684. doi: 10.1172/jc1141714. 

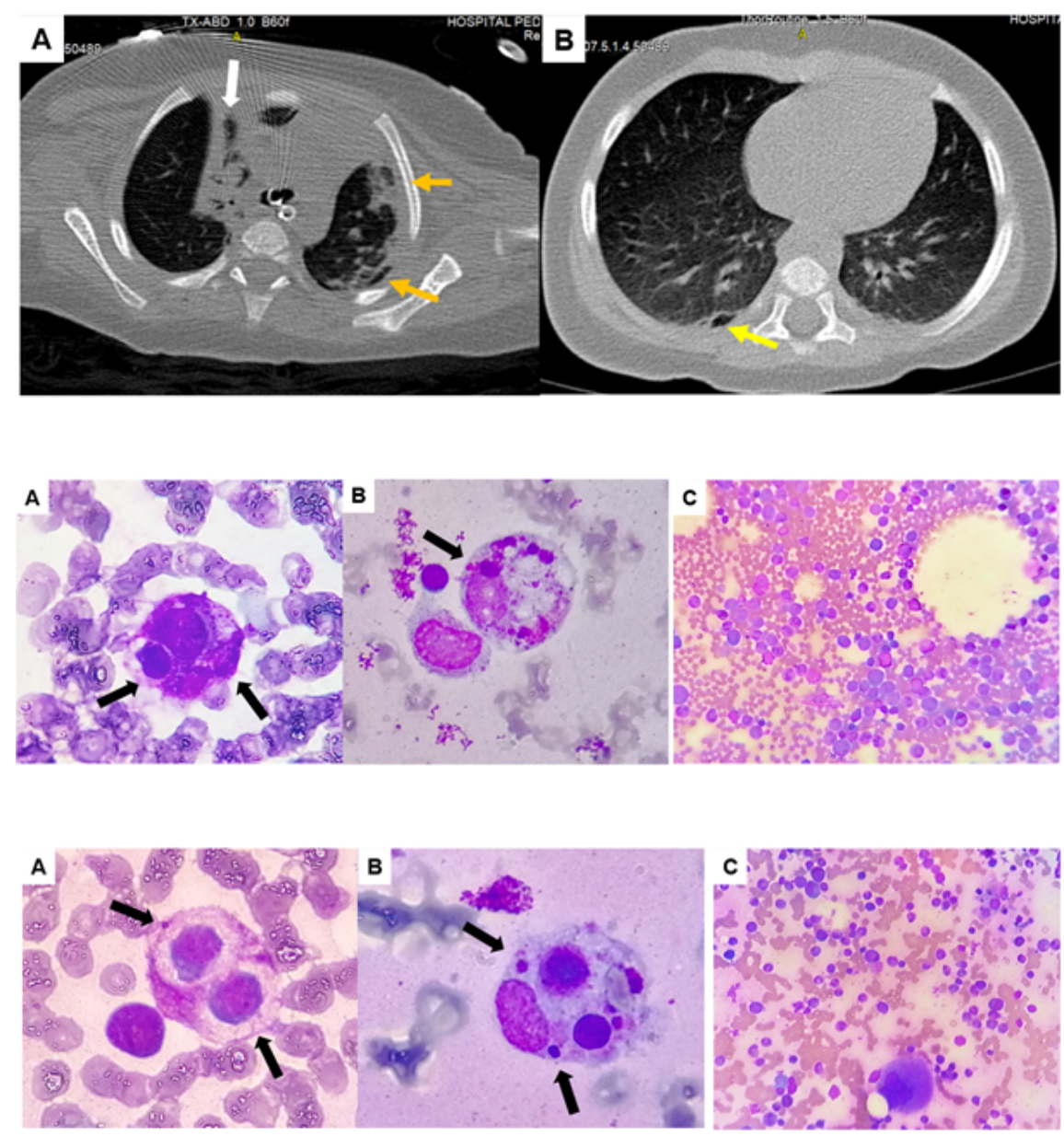